\title{
A clear direction
}

\section{The process established by the Intergovernmental Panel on Climate Change has generated a sound foundation of knowledge on which policy-makers must now build.}

$\Lambda$ nd so, for another six years at least, it is over. Thousands of authors referring to vast numbers of papers have, in sometimes-contested consultation with the governments that lend their name to the process, provided the world with their best assessment to date of humanity's prospects and options in the matter of climate change.

The Intergovernmental Panel on Climate Change (IPCC) is far from a perfect institution, but it is a necessary and a heartening one. To see the governments of the world almost unanimously acknowledge that they share a problem, and set up a process for identifying its scope that is rooted in the impartial norms of science, is in itself a reason for hope about the century ahead.

The final contribution to the IPCC's fourth assessment report is, as we report on page 120, a rather upbeat one. Shifts in the way the world generates and uses energy can, the panel says, reduce the risks of climate change in exchange for only a fairly small slowing in the rate of growth of GDP. Various ways of bringing about such shifts are discussed. But perhaps because the IPCC is devoted to consensus, the relative merits of those schemes are not explored.

This is because two economists, or for that matter two nations, can agree on their analysis of the subject but still differ on what needs to be done. That decision rests in the political sphere.

The G8 summit in Heiligendamm, Germany, next month will offer powerful nations the chance to discuss the merits of opting en masse for the European Union's policy of halving carbon dioxide emissions by 2050 . Six months later, in Bali, Indonesia, the countries that have signed up to the United Nations Framework Convention on Climate Change and the Kyoto Protocol will be able to begin the process of thrashing out what to do next - specifically, whether to extend and expand the Kyoto Protocol when its first commitment period comes to an end in 2012, or replace it with something else. However it develops, this stage must reaffirm the Kyoto goal of broad and coordinated reductions but must apply it more widely than the current protocol. Just as Kyoto was deeply flawed by the decision of the world's largest emitter of carbon dioxide to remain outside it, so the next agreement will be flawed if the same is true after 2012 - even though, by then, the potential holdout would be by China, not the United States.

There are no concrete plans for a fifth IPCC assessment before 2012. But some sort of continuity in the assessment of where the science of climate change is headed, its foreseeable impacts and the tools at policy-makers' disposal is a high priority.

It is unavoidable that many climate scientists care deeply about their work's implications, and quite proper, as this process unfolds, that they should make their concerns heard. But scientists and their managers also have a duty to explore all the options - and to put aside their personal preferences in offering advice to governments. In this, the community has not always been beyond reproach.

One research area that has been ignored, in part because of prior ideological commitments, is geoengineering, which explores in what circumstances aspects of the climate system might be deliberately modified to limit the worst eventualities of climate change (see page 132). It is true that some bizarre projects fall under that name - notably, various ill-conceived schemes for fertilizing the oceans. But the idea that more active management of soil carbon could offset future emissions is sound (see page 143).

It would be far better for such ideas to be examined scientifically - and their failings thus held up to scrutiny - than not. Those scientists who have started to raise this debate deserve thanks, support and, of course, rigorous criticism from their colleagues. In climate research and beyond, it is important to remember that the value of scientists' work comes not just from the research and expertise that allows them to inform debates, but also from the object lesson they provide in the ways in which a community rich in specialities and diverse interests can come to a comprehensive and objective overview.

\section{Starting at the top}

\section{Scientific élites retain a severe gender imbalance.}

S eventy-two names are on the list of new members of the US National Academy of Sciences, elected on 1 May. Nine stand out: Tania Baker, Ursula Bellugi, Karen Cook, Mary Estes, Pamela Fraker, Angela Gronenborn, Helen Hobbs, Laura Kiessling and Eve Marder.

Two years ago, the academy elected 19 women to its ranks; this year, the number is less than half of that. Over the years there have been a plethora of programmes designed to introduce women into science, and more sporadic efforts to keep them in the career pipeline while they bear and raise children. Yet women have still not come remotely close to closing the gender gap at the senior level.

Of course, some women do reach the scientific élite: at its meeting last week, the academy awarded its highest honour, the Public Welfare Medal, to biologist Maxine Singer. But Singer has little female company at the top of the scientific hierarchy.

Roughly $10 \%$ of members of the science academy are women. This is up from just $6 \%$ in 2000, but is still a disappointing number. Even as the percentage of women rises in many research fields, women still find it harder to join the scientific élite - even in the United States, where they have had a firmer foothold for longer than elsewhere.

As US science's most exclusive club, the academy is fully aware that its membership is dominated by white males of a certain age, and has made attempts to address the fact. New members are nominated and 
elected by other members - which is, of course, a recipe for perpetuating such bias. But some of the academy's 31 discipline-based sections have adopted proactive schemes for identifying promising female candidates, and a set of nominating groups established in 2003 helps more women and younger candidates enter the mix of potential members. The Royal Society in London has also made efforts in the past five years to increase the number of women in its ranks.

Such measures are to be applauded, but they don't seem to be working as well as they might. Options for a more direct assault on the issue are problematic, however. Setting up any kind of quota system, for example, would trigger a cascade of difficulties, starting with the possibly diminished status of women elected as part of a quota.

A slightly higher cap on the number of members admitted each year might better reflect the growing size and academic diversity of the scientific community, and open up the pipeline a little for deserving candidates of both sexes. But it would do little to address the gender imbalance.

Perhaps the best thing the academy can do is find ways to get suitably qualified women on the ballot in each of its sections. Such a change may, for instance, require a stipulation that nominees from diverse backgrounds will at least appear on the ballot.

\section{Under the microscope}

\section{The use of 'black box' techniques carries risks.}

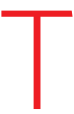
he apparatus list for a modern biology experiment is a far cry from the trusty pipette and centrifuge. A sophisticated and costly fluorescence microscope for exposing intricate cellular structures is often essential. So too are suites of software for bioinformatics and image analysis, a machine for sorting cells, and sophisticated computer models.

Mastering just one of these techniques can be a full-time job, yet a researcher may need several of them to gather data for a paper. Many biologists lack a detailed grasp of how the increasingly sophisticated techniques that they are using actually work (see page 138). As a result, they sometimes risk making innocent but nonetheless substantial errors.

Part of the problem can be attributed to the different approaches towards scientific equipment associated with different disciplines. Physicists, for example, have a long tradition of building their own equipment, and are often fascinated by its mechanics. Biologists' fascination is primarily with the mechanics of nature and, for many, the machines themselves are simply tools - complicated 'black boxes' that produce the results they need. It doesn't help that the tools biologists are using may have been designed by physicists, and that the two groups tend to use different jargon.

There are plenty of exceptions to this pattern. Some leaders in biological imaging, for example, have backgrounds in engineering and custom-build their own apparatus. But more typically, when life-science laboratories invest in an expensive new microscope, for example, only the first generation of users are properly trained in its use. As that knowledge is passed from person to person it can become
Academy members at all levels should also take a more prominent and public role in promoting initiatives that will secure fair treatment for women scientists. All too often, discussions about advancing women or minorities in science spring from the same people - usually the women or minorities themselves. Some leaders do get involved, but it is up to them all to recognize that broadening diversity is more than just a feelgood effort, something to chalk up as a good deed done in the name of equality and then be forgotten.

A new initiative in US physics is to be applauded for taking steps in this direction. On 6-8 May, the chairs of 50 physics departments, plus 15 senior managers from national laboratories, met in College Park, Maryland, to discuss how to double the number of women in physics by 2022. The fact that a number of high-level researchers attended is cause for optimism. It remains to be seen how this effort will develop over time, but other fields would do well to consider similar moves.

Women in the United States have been told for decades that they need to enter science at the bottom in order to make their way to the top. But this situation has been going on for too long. Those already in the scientific élite must take it upon themselves to bring about genuine gender equity.

dated or even distorted - and when the resident expert leaves, the knowledge often leaves with them. In the same vein, researchers may trustingly plug their data into a computer program for bioinformatics or image processing, without really understanding what the software is doing.

Ignorance of these black boxes can get researchers into trouble. Take the situation of Geoffrey Chang, a protein crystallographer at the Scripps Research Institute who didn't know that the software he was using to determine protein structures contained an error. $\mathrm{He}$ subsequently had to retract five papers because of the oversight (see Science 314, 1875; 2006). More commonly, ignorance of the machinery creates minor setbacks, such as hours spent trying to repeat an imaging experiment when the initial report was actually the result of shoddy microscopy.

Individual researchers cannot be expected to know the minutiae of every instrument or technique they use, but a basic grasp of the principles and operation should be a professional requirement. In the case of microscopy, biologists should try to attend courses that provide a basic knowledge of optics, as well as some hands-on experience, to provide a foundation for operating the instrument.

Equally, researchers should admit to themselves what they do not know and seek out the missing expertise. The collaboration of specialists, either from within the same institution or outside, should be sought early during experimental design and, where appropriate, acknowledged in the resulting paper's author list.

For young scientists, the aversion of some of their colleagues to an intimate knowledge of instruments and techniques presents an opportunity. There is a fascination in being immersed in the mechanisms of microscopes, or in mastering the statistics behind sequence searches. People who can ask fundamental questions in biology and have mastered a sophisticated technique will never be short of a job. It really pays to know your apparatus inside out. 